\title{
ANALISIS RISIKO KEGAGALAN DAN BASIC CAUSE KEBOCORAN PADA TANGKI PENYIMPANAN AMONIA
}

\author{
FAILURE RISK AND BASIC CAUSE ANALYSIS OF \\ AMMONIA STORAGE TANK LEAKAGE
}

\author{
Mirna Apriani*1), Ahmad Rizeki ${ }^{1)}$, dan Agung Nugroho ${ }^{1)}$ \\ 1) Program studi Teknik Keselamatan dan Kesehatan Kerja, Politeknik \\ Perkapalan Negeri Surabaya \\ *Email: mirnaapriani@gmail.com
}

\begin{abstract}
Abstrak
Amonia merupakan bahan kimia bahan berbahaya dan beracun, dapat menimbulkan luka bakar bahkan kematian. Pelepasan amonia dari tangki penyimpanan memiliki potensi bahaya bagi pekerja dan manusia di lingkungan sekitar. Amonia cair mudah terlepas ke lingkungan karena dapat berubah menjadi gas pada temperatur ruang. Penelitian dilakukan untuk menganalisis risiko tinggi dan menentukan basic cause kebocoran pada tangki penyimpanan. Analisis risiko tinggi didahului dengan identifikasi potensi bahaya menggunakan metoda Failure Mode Equipment Analysis (FMEA). Untuk mengetahui basic cause dilakukan menggunakan Fault Tree Analysis (FTA). Hasil FMEA didapatkan risiko tertinggi adalah fail close flow control valve. (FCV). Hasil FTA basic cause dari fail close FCV adalah perawatan buruk, umur pemakaian, pressure indicator error/jarang dikalibrasi. Pencegahan kegagalan semua komponen yang mendukung kinerja FCV adalah perawatan sesuai jadwal agar dapat mencegah kerusakan sebelum masa efektif komponen. Selain perawatan sesuai jadwal juga dilakukan pelatihan kepada operator agar kompeten untuk mengurangi human error.
\end{abstract}

Kata kunci: amonia, FMEA, FTA, basic cause, risiko tinggi

\section{Abstract}

Ammonia is a hazardous materials, can cause burns and even death. The release of ammonia from storage tanks has the potential hazard to workers and people in the neighborhood. Liquid ammonia is released easily into the environment because it can turn into gas at room temperature. The study was conducted to analyze the high risk and determine the basic cause leaks in storage tanks. High risk analysis will be preceded by the identification of the potential hazard of using the method Equipment Failure Mode Analysis (FMEA). Fault Tree Analysis (FTA) used to analysis the basic cause. FMEA results obtained the highest risk is flow control valve (FCV) fail to close. FTA result basic cause of fail close FCV is bad maintenance, life time, pressure indicator error/rarely calibrated. Prevention of failure of all the components that support the performance of $F C V$ is the maintenance schedule in order to prevent damage before the effective life of the components. To eliminate the human error, training for upgrading the operator compentency to to reduce human error has to be conducted.

Keywords: ammonia, FMEA, FTA, basic cause, high risk 


\section{PENDAHULUAN}

Amonia memiliki titik didih normal $-33^{\circ} \mathrm{C}$ pada tekanan atmosfer. Untuk memudahkan dalam penanganannya, amonia disimpan di dalam tangki dalam kondisi cair. Amonia merupakan bahan kimia termasuk dalam kategori bahan berbahaya dan beracun, bersifat korosif dan menimbulkan luka bakar (White, 1971; Lewis, 1996; Bai et al., 2006) yang dapat menyebabkan iritasi dan luka pada jaringan halus seperti hidung, trakea, paru-paru dan bagian tubuh lain yang terpapar (Asfahl, 1999; Plog dan Quinlan, 2002). Iritasi dapat terjadi pada mata, kulit, hidung dan saluran pernafasan atas. Pemaparan kronis dapat menyebabkan terjadinya penurunan fungsi paru-paru. Pemaparan akut dapat menyebabkan mata meradang sampai kebutaan dan menyebabkan kejang otot dan mempengaruhi sistem saraf (White, 1971; Bai et al., 2006).

Pelepasan amonia dari tangki penyimpanan memiliki potensi bahaya bagi pekerja dan manusia di lingkungan sekitar (Bhattercharjee et al., 2012). Amonia cair mudah terlepas ke lingkungan karena dapat berubah menjadi gas pada temperatur ruang (Jie et al., 2014; Roy et al., 2011). Pelepasan amonia akibat kebocoran pada proses penyimpanan menimbulkan kematian di Baoshan district Shanghai pada tahun 2013 (Yilang et al., 2014). Pelepasan amonia termasuk ke dalam kategori risiko tinggi (ILO, 1991).

Pencegahan pelepasan amonia perlu dilakukan untuk keselamatan dan kesehatan pekerja dan masyarakat sekitar serta untuk mencegah terjadinya kerugian material. Pencegahan dapat dilakukan apabila telah didapatkan kemungkinan penyebabnya. Penyebab kebocoran tangki harus dilihat secara keselurahan pada sistem penyimpanan. Sistem penyimpanan tangki dilengkapi dengan beberapa peralatan yang saling mendukung. Apabila terjadi kegagalan pada peralatan maka dapat menimbulkan terjadinya kebocoran (Asfahl, 1999). Untuk menghindari terjadinya kegagalan peralatan maka dilakukan identifikasi setiap komponen berdasarkan fungsinya. Identifikasi kemungkinan kegagalan diikuti dengan penyebab, jenis kegagalan, dampak dan peluang sehingga bisa dilakukan analisis risiko. Analisis risiko akan menghasilkan komponen kritis penyebab kegagalan. Komponen kritis ini akan dianalisis untuk mendapatkan basic cause. Basic cause dapat digunakan sebagai pertimbangan untuk penentuan pengendalian risiko (Kavianian et al., 1990; Burlikowska, 2011; Rakesh et al., 2013.

Identifikasi kemungkinan terjadinya kegagalan komponen dan analisis risiko menggunakan Failure Modes and Effects Analysis (FMEA). Kemudian dilanjutkan analisis basic cause menggunakan Fault Tree Analysis (FTA). FMEA adalah metoda yang sistematis mengidentifikasi peralatan/equipment penyebab kegagalan sistem dan dampak dari masingmasing kegagalan. Kegagalan setiap komponen dianalisis meliputi mode kegagalan, efek/dampak dalam kinerja peralatan tersebut (Kavianian et al., 1990; Plog et al.,2002). Setiap peralatan mempunyai mekanisme masingmasing untuk mencapai kegagalannya. Melalui FMEA bisa dihasilkan komponen/peralatan kritis yang dapat dijadikan sebagai preventive maintenance melalui kegiatan inspeksi dan penggantian komponen sebelum terjadi kegagalan. FMEA dilakukan secara kualitatif, kemudian melalui data kuantitatif yang bisa menunjukan ranking risiko kritikal dari kemungkinan kegagalan sistem yang sering terjadi (Asfahl, 1999; Burlikowska, 2011; Sultan et al., 2011; Rakesh et al., 2013). Komponen yang merupakan kategori risiko tinggi akan dilanjutkan dengan menganalisis untuk mendapatkan basic cause yang menyebabkan kecelakaan. Analisis yang dilakukan adalah dengan menggunakan FTA.

FTA mempertimbangkan semua penyebab dari procedural dan/atau peralatan (Asfahl, 1999; Yilang et al., 2014; Roy et al., 2011). FMEA tidak mempertimbangkan kesalahan manusia dan konsentrasi studi adalah pada komponen sistemnya bukan pada hubungan sistem yang sering menyebabkan kegagalan. Sehingga perlu 
dilanjutkan dengan FTA. FTA adalah metode identifikasi potensi bahaya yang mendemonstrasikan hubungan antara kegagalan peralatan, kesalahan manusia dan faktor lingkungan yang dapat menghasilkan peluang terjadinya kecelakaan (Kavianian et al., 1990).

Tujuan penelitian ini adalah untuk melakukan analisis risiko dan basic cause kebocoran tangki penyimpanan amonia dengan metoda FMEA dan FTA.

\section{METODA}

Data yang dikumpulkan meliputi data primer dan data sekunder. Data primer merupakan data yang diperoleh melalui proses observasi dan hasil wawancara. Proses observasi dilakukan untuk mengetahui sistem penyimpanan tangki dan peralatan pengamanannya. Wawancara dilakukan untuk mendapatkan informasi mengenai jenis kegagalan dan penyebabnya, peluang kejadian dan dampaknya, sistem operasional tangki penyimpanan. Data sekunder meliputi lay out tangki penyimpanan, functional block diagram (FBD), prosedur perusahaan penerapan manajemen risiko, data kegagalan, material safety data sheet (MSDS).

Langkah-langkah pembuatan FMEA adalah (1) menentukan batasan yang akan dianalisis (2) menyusun worksheet yang terdiri dari deskripsi: equipment, function, functional function, description of failure (failure mode, failure mechanism, detection offailure), effect of failure, dampak, peluang dan tingkat risiko, dan (3) menentukan dampak dan peluang dari setiap kejadian kegagalan peralatan untuk mendapatkan risiko (Kavianian et al., 1990; Burlikowska, 2011; Rakesh et al., 2013).

Risiko dapat dihitung menggunakan rumus berikut ini :

$$
\text { Risiko }=\text { dampak } \mathrm{x} \text { peluang }
$$

Skala pengukuran "dampak" didasarkan pada kriteria yang berdampak pada performance indicator terhadap pencapaian tujuan perusahaan. Skala pengukuran "peluang" didasarkan pada kriteria yang berpeluang mengganggu terhadap performance indicator. Skala pengukuran dampak dan peluang dapat dilihat pada Tabel 1.

Tabel 1. Klasifikasi dampak dan peluang

\begin{tabular}{|c|c|c|c|c|c|}
\hline Ranking & Klasifikasi & Dampak & Ranking & Klasifikasi & Peluang \\
\hline 1 & Insignificant & $\begin{array}{l}\text { Dampak } \\
\text { tidak } \\
\text { signifikan }\end{array}$ & 1 & Rare & $\begin{array}{l}\text { sangat } \\
\text { kecil/jarang } \\
(0-20 \%)\end{array}$ \\
\hline 2 & Minor & $\begin{array}{l}\text { Dampak } \\
\text { kecil }\end{array}$ & 2 & Unlikely & $\begin{array}{l}\text { Cnkmp/sekali- } \\
\text { sekali } \\
(>20-40 \%)\end{array}$ \\
\hline 3 & Moderate & $\begin{array}{l}\text { Dampak } \\
\text { sedang }\end{array}$ & 3 & Moderate & $\begin{array}{l}\text { Sedang } \\
(>40-60 \%)\end{array}$ \\
\hline 4 & Major & $\begin{array}{l}\text { Dampak } \\
\text { besar }\end{array}$ & 4 & Likeby & $\begin{array}{l}\text { Sering } \\
(>60-80 \%)\end{array}$ \\
\hline 5 & Catastrophic & $\begin{array}{l}\text { Dampak } \\
\text { signifikan }\end{array}$ & 5 & Certain & $\begin{array}{l}\text { Hampir selahu } \\
\text { terjadi/pasti } \\
\text { (>80-100\%) }\end{array}$ \\
\hline
\end{tabular}

Sumber : Petrokimia, 2010

PT Petrokimia Gresik mengelompokkan risiko menjadi 3 (tiga) tingkatan, yaitu: (1) tinggi : nilai $>12-25$ (2) sedang: nilai $>4-12$ (3) rendah : nilai $1-4$. Peralatan yang mempunyai nilai risiko tinggi merupakan peralatan kritis yang akan dianalisis basic cause nya.

Langkah-langkah dari pembuatan FTA adalah (1) menentukan kejadian yang tidak diinginkan/kecelakaan/top event (2) melalukan analisis sistem melalui gambar desain, spesifikasi peralatan, pustaka, dan prosedur operasional serta informasi lain yang tersedia (3) menyusun fault tree yang dimulai dari top event dan cabang dari fault tree. Kemudian menentukan kemungkinan kegagalan peralatan, kesalahan manusia atau faktor lingkungan yang dapat menyebabkan terjadinya top event yang digambarkan sebagai cabang dari fault tree. Cabang diteruskan sampai mendapatkan independent event/basic cause (Kavianian et al., 1990; Plog et al., 2002).

\section{HASIL DAN PEMBAHASAN}

\section{Functional block diagram (FBD)}

FBD dari tangki penyimpanan disajikan dalam Gambar 1. FBD digunakan sebagai pedoman untuk menentukan peralatan yang mendukung kinerja tangki penyimpanan. FBD juga 
menjelaskan fungsi dari peralatan yang mendukung tangki penyimpanan.

Untuk memudahkan dalam penyimpanannya, amonia disimpan dalam kondisi cair. Prinsip dasar penyimpanan adalah menjaga tekanan dalam tangki agar amonia tetap dalam kondisi cair. Untuk menjaga tekanan tangki dilengkapi compressor refrigerant, evaporator, pressure safety valve, incinerator, emergency main valve. Tangki dipertahankan dalam kondisi keseimbangan melalui panas yang masuk. Panas tersebut untuk proses evaporasi (menguapkan ammonia). Uap yang terbentuk terus menerus akan dapat menaikan tekanan tangki yang bisa membahayakan jika tidak terkontrol. Uap yang terbentuk akan mengalami proses pengembunan melalui sistem refrigerasi. Proses di atas memiliki potensi bahaya terjadi pelepasan ammonia ke lingkungan melalui kebocoran atau ledakan.

\section{Failure mode equipment analysis (FMEA)}

Pada penelitian ini FMEA dilakukan pada semua peralatan yang mendukung operasional tangki penyimpanan. Peralatan terdiri dari tangki penyimpanan, line pipa $\mathrm{NH}_{3}$, pompa (P-806), pompa (02-P-801 A, B), block valve, vacuum breaker, flow control valve (FVC-860), evaporator, incinerator, pressure safety valve, compressor refrigerant, emergency main valve. Setiap peralatan dilakukan analisis mengenai function, fuctional failure, description of failure, effect of failure, dampak, peluang dan tingkat risiko. Contoh analisis FMEA yang merupakan peralatan kritis dapat dilihat pada Tabel 2 . Peralatan kritis dari hasil FMEA adalah FCV860 dengan nilai dampak sebesar 4 dan nilai peluang sebesar 4. Sehingga nilai risiko kegagalan FCV sebesar 16 dan ini termasuk ke dalam tingkatan kategori risiko tinggi (Petrokimia, 2014).

\section{Fault tree analysis (FTA)}

FTA pada jurnal ini akan ditampilkan dalam bentuk tabel yang terdiri dari top event, Intermediate Event (EI) 1 sampai dengan 4 dan basic cause. FTA disajikan pada Tabel 3. Untuk membedakan hubungan antara EI dan basic cause yang bersifat "and" atau "or", dibedakan melalui penulisannya. Untuk EI dan basic cause dengan hubungan "and" akan ditulis dengan dilengkapi garis bawah.

Berdasarkan hasil FMEA didapatkan risiko tinggi pada sistem tangki penyimpanan adalah pelepasan melalui kebocoran. Maka top event dari FTA adalah kebocoran pada tangki amonia. Tangki penyimpanan dapat mengalami kebocoran (top event) apabila terdapat intermediate event (IE-1): kualitas material menurun, over pressure tank, sambungan pipa inlet bocor atau low pressure tank. Dengan tanda penghubung "or" yang menunjukan bahwa top event dapat terjadi dengan salah satu IE-1 saja. Jika kualitas material menurun meskipun tidak terjadi over pressure tank maka kebocoran pada tangki amonia akan tetap terjadi.

Kualitas tangki menurun (IE-1) akan terjadi apabila terdapat IE-2: treatment tangki jarang/tidak berkala, tangki korosi dan material tangki mengalami penipisan dan fatigue. Ketiga IE-2 dihubungkan dengan tanda "and". Maka akan terjadi kualitas material menurun jika ketiga IE-2 terjadi secara bersamaan. Basic cause treatment tangki jarang: inspeksi dan pengawasan jarang atau tidak dilakukan uji tangki berkala. Basic cause tangki korosi: lapisan cat mengelupas dan gas sintesa amonia menitridasi logam. Basic cause material tangki mengalami penipisan dan fatigue: perawatan buruk atau umur pemakaian.

Sambungan pipa inlet bocor (EI-1) akan terjadi apabila terdapat (EI-2): fail close FCV-860, line pipa $\mathrm{NH}_{3}$ over pressure dan daya tahan sambungan terbatas. Ketiga IE-2 dihubungkan dengan tanda "and". Maka akan terjadi kualitas material menurun jika ketiga IE-2 terjadi secara bersamaan. Fail close FCV-860 (EI-2) akan terjadi apabila terdapat IE-3: perbedaan tekanan di dalam tangki penyimpanan dan tekanan input, kesalahan setting tekanan FCV atau flow indicator (FI-860) rusak. Ketiga IE-3 dihubungkan dengan tanda "or" sehingga salah satu IE-3 terjadi maka fail close akan terjadi. 
Perbedaan tekanan di dalam tangki (EI-3) akan terjadi disebabkan adanya EI-4 (pressure indicator) atau basic cause (pemeriksaan di lapangan oleh operator control room amonia. Basic cause EI-4 (pressure indicator): perawatan buruk dan umur pemakaian. Basic cause kesalahan setting tekanan FCV (EI-3): human error atau pressure indicator error/jarang dikalibrasi. Basic cause flow indicator (FI-860) rusak (EI-3): perawatan buruk atau umur pemakaian.

Line pipa $\mathrm{NH}_{3}$ over pressure (EI-2) akan terjadi apabila terdapat EI-3: build up pressure pada pipa dan block valve (BV-A) gagal menutup. Build up pressure pada pipa (EI-3) disebabkan kerusakan komponen pipa (EI-4) atau basic cause kesalahan setting pompa. Basic cause kerusakan komponen pipa (EI-4): perawatan buruk atau umur pemakaian. Block valve (BV-A) gagal menutup (EI-3) disebabkan karena EI-4: kerusakan komponen atau block valve leak. Basic cause dari kedua EI-4: perawatan buruk atau umur pemakaian.

Over pressure tank (EI-1) akan terjadi apabila terdapat EI-2: pressure safety valve (PSV-872) tidak berfungsi dan build up pressure tank. Kedua IE-2 dihubungkan dengan tanda "and". Maka akan terjadi over pressure tank jika kedua IE-2 terjadi secara bersamaan. Pressure safety valve (EI-2) akan terjadi jika pressure safety jarang dikalibrasi (basic cause) dan terdapat kerusakan komponen spring/per (EI-3). EI-3 akan terjadi jika terdapat basic cause: umur pemakaian, tekanan melebihi desain $(>100$ $\mathrm{g} / \mathrm{cm} 2$ ) atau perawatan buruk.

Build up pressure tank (EI-2) akan terjadi jika terdapat EI-3: refrigerant tidak bekerja secara maksimal dan indikator tekanan tidak berfungsi. Basic cause indikator tekanan tidak berfungsi: pressure gauge rusak atau jarang dikalibrasi. Refrigerant tidak bekerja secara maksimal (EI-3) terjadi jika terdapat EI-4: masalah mekanis atau failed to pump. Basic cause masalah mekanis: kerusakan komponen compressor atau umur pemakaian. Failed to pump (EI-4) terjadi apabila terdapat gangguan listrik (EI-5), basic cause: gasket cylinder head bocor atau katup discharge dan suction bocor. Basic cause gangguan listrik (EI-5): listrik drop/mati atau switch ke PLN membutuhkan waktu lama.

Low pressure tank (EI-1) akan terjadi apabila terdapat (EI-2): evaporator tidak bekerja maksimal, vacuum breacker (VB-872) tidak bekerja maksimal dan indikator tekanan tidak berfungsi. Ketiga IE-2 dihubungkan dengan tanda "and". Maka akan terjadi low pressure tank jika ketiga IE-2 terjadi secara bersamaan. Evaporator tidak berkerja maksimal terjadi apabila terjadi EI-3: tekanan $\mathrm{NH}_{3}$ kecil atau $\mathrm{NH}_{3}$ lama panas. Basic cause tekanan $\mathrm{NH}_{3}$ kecil: tekanan $\mathrm{NH}_{3}$ yang masuk terlalu rendah atau strainer kotor/tersumbat. $\mathrm{NH}_{3}$ lama panas (EI-3) terjadi apabila terdapat electric heater rusak (EI4) atau gangguan listrik (basic cause). Basic cause EI-4: umur pemakaian atau perawatan buruk. Vacuum breaker tidak bekerja maksimal (EI-2) terjadi akibat adanya masalah teknik (EI3) atau tekanan $\mathrm{NH}_{3}$ kecil (basic cause). Basic cause masalah mekanis (EI-3): kerusakan komponen atau umur pakai. Indikator tekanan tidak berfungsi (EI-2) terjadi disebabkan karena pressure gauge rusak atau jarang dikalibrasi.

Basic cause yang dihasilkan dari metoda FTA dapat digunakan sebagai pedoman untuk pencegahan terjadinya pelepasan amonia. Basic cause yang sering muncul pada analisis FTA adalah umur pemakaian, perawatan buruk, kesalahan setting, kerusakan komponen. Perawatan buruk disebabkan karena perawatan yang dilakukan tidak sesuai jadwal dan hanya bersifat kondisional. Umur pemakaian komponen dipengaruhi oleh kondisi perawatannya. Kerusakan komponen jika telah memasuki masa efektif pemakaiannya dapat diketahui dari spesifikasi komponen. Kerusakan komponen yang terjadi sebelum masa efektif pemakaian disebabkan karena perawatan buruk. Kesalahan setting pada pengoperasian bisa terjadi akibat operator yang tidak memahami prosedur operasional.

Sistem penyimpanan amonia berdasarkan kondisi operasi untuk menjaga amonia tetap berada dalam kondisi cair. Menurut Roy et al., 
(2011) penyimpanan amonia terdiri dari tiga metode yaitu (1) penyimpanan bertekanan dengan temperatur ambien (2) penyimpanan atmospheric pada suhu $-33^{\circ} \mathrm{C}$ (3) penyimpanan tertutup dengan tekanan hingga $0^{\circ} \mathrm{C}$.

Intermediate event yang dapat menimbulkan risiko tinggi adalah fail close FCV. Prioritas pengendalian perusahaan diutamakan pada failure fuction yang menyebabkan terlepasnya amonia. Basic cause dari fail close FCV adalah perawatan buruk, umur pemakaian, pressure indicator error/jarang dikalibrasi. Pencegahan kegagalan semua komponen yang mendukung kinerja FCV adalah perawatan sesuai jadwal agar dapat mencegah kerusakan sebelum masa efektif komponen. Selain perawatan sesuai jadwal juga dilakukan pelatihan kepada operator agar kompeten untuk mengurangi human error. Pihak manajemen harus menyediakan pelatihan untuk meningkatkan kompetensi, kesadaran akan pentingnya keselamatan dan kesehatan dan melakukan pengawasan (Yilang et al., 2014).

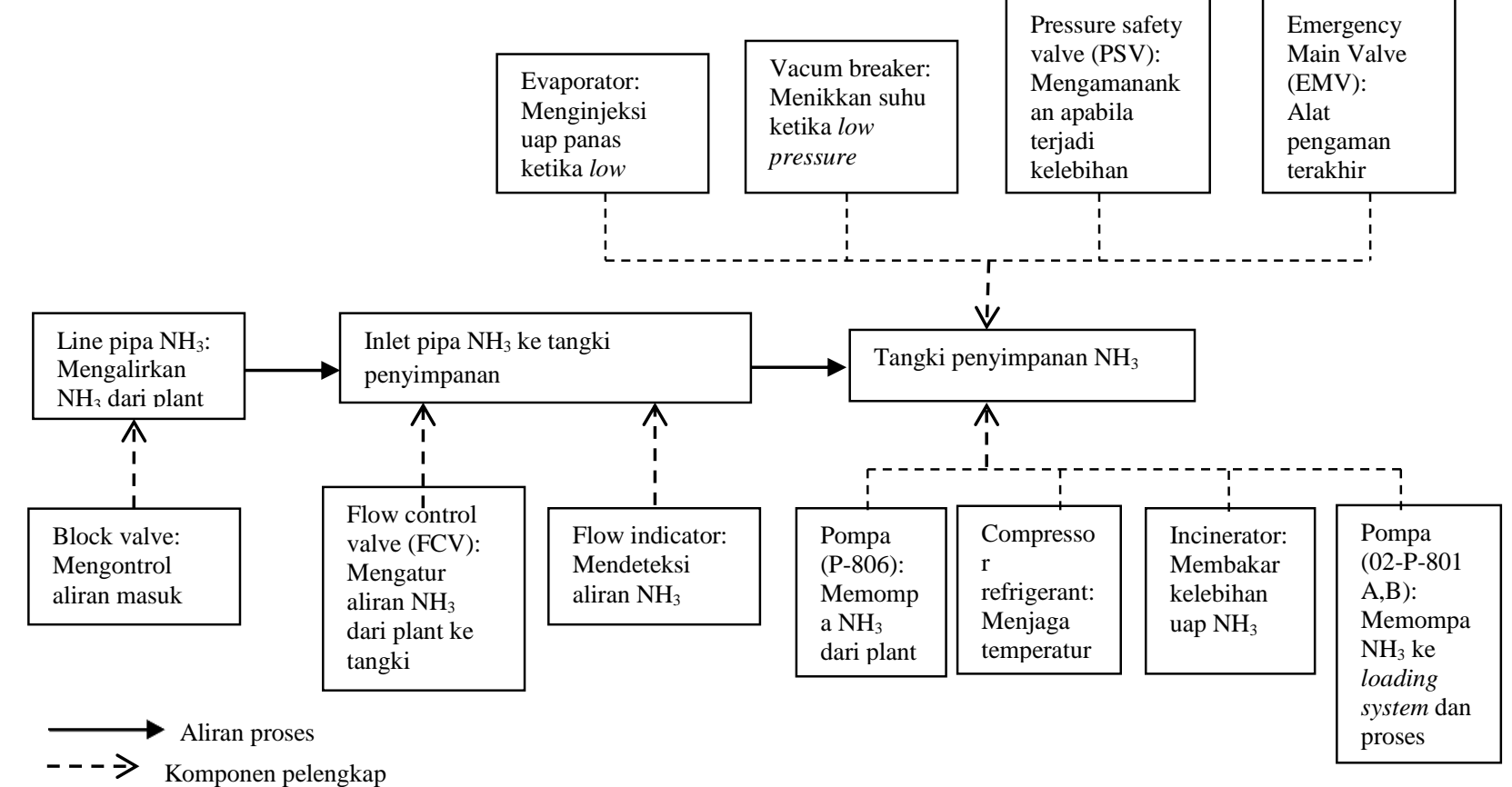

Gambar 1 FBD tangki penyimpanan ammonia

Tabel 2. FMEA

\begin{tabular}{|c|c|c|c|c|c|c|c|c|c|c|}
\hline \multirow{2}{*}{ Equipment } & \multirow{2}{*}{ Function } & \multirow{2}{*}{$\begin{array}{c}\text { Functional } \\
\text { failure }\end{array}$} & \multicolumn{3}{|c|}{ Description of failure } & \multirow{2}{*}{ Effect of failure } & \multirow{2}{*}{$\begin{array}{c}\text { Dampak } \\
\text { (D) }\end{array}$} & \multirow{2}{*}{$\begin{array}{c}\text { Peluang } \\
(\mathrm{P})\end{array}$} & \multirow{2}{*}{$\begin{array}{c}\text { Risiko } \\
\text { (D) } \mathrm{x}(\mathrm{P})\end{array}$} & \multirow{2}{*}{$\begin{array}{c}\text { Kategori } \\
\text { risiko }\end{array}$} \\
\hline & & & Failure mode & $\begin{array}{c}\text { Failure } \\
\text { mechanism }\end{array}$ & $\begin{array}{l}\text { Detection of } \\
\text { failure }\end{array}$ & & & & & \\
\hline \multirow[t]{2}{*}{$\begin{array}{c}\text { Flow } \\
\text { control } \\
\text { valve } \\
\text { (FCV-860) }\end{array}$} & \multirow[t]{2}{*}{$\begin{array}{c}\text { Mengatur } \\
\text { aliran amonia } \\
\text { dari plant } \\
\text { amonia ke } \\
\text { tangki } \\
\text { penyimpanan }\end{array}$} & \multirow[t]{2}{*}{$\begin{array}{c}\text { Fail close } \\
\text { FCV }\end{array}$} & $\begin{array}{l}\text { Kesalahan } \\
\text { setting } \\
\text { tekanan yang } \\
\text { diinginkan }\end{array}$ & $\begin{array}{l}\text { Pressure } \\
\text { indicator } \\
\text { jarang } \\
\text { dikalibrasi }\end{array}$ & $\begin{array}{l}\text { Tekanan yang } \\
\text { diinput tidak } \\
\text { terbaca di } \\
\text { monitor } \\
\text { control room }\end{array}$ & $\begin{array}{l}\text { Aliran amonia } \\
\text { berlebihan, bisa } \\
\text { meny ebabkan } \\
\text { pelep asan amonia } \\
\text { melalui kebocoran }\end{array}$ & 4 & 4 & 16 & tinggi \\
\hline & & & $\begin{array}{l}\text { Perbedaan } \\
\text { tekanan di } \\
\text { dalam tangki } \\
\text { penyimpanan } \\
\text { dan tekanan } \\
\text { input }\end{array}$ & $\begin{array}{l}\text { Pressure } \\
\text { indicator } \\
\text { jarang } \\
\text { dikalibrasi }\end{array}$ & $\begin{array}{l}\text { FCV tidak } \\
\text { melakukan } \\
\text { auto close off }\end{array}$ & $\begin{array}{l}\text { Tekanan di dalam } \\
\text { tangki terus } \\
\text { meningkat bisa } \\
\text { meny ebabkan } \\
\text { terjadiny a ledakan }\end{array}$ & 5 & 1 & 5 & sedang \\
\hline
\end{tabular}




\section{Tabel 3. FTA}

\begin{tabular}{|c|c|c|c|c|c|}
\hline Top Event & Intermediate event 1 & Intermediate event 2 & Intermediate event 3 & Intermediate event 4 & Basic cause \\
\hline \multirow{24}{*}{$\begin{array}{l}\text { Tangki } \\
\text { penyimpanan } \\
\text { mengalami } \\
\text { kebocoran }\end{array}$} & \multirow{6}{*}{$\begin{array}{l}\text { 1. Kualitas material tangki } \\
\text { menurun }\end{array}$} & 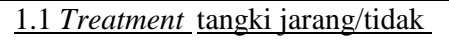 & & & 1.1.1 Inspeksi dan pengawasan jarang \\
\hline & & $\underline{\text { berkala }}$ & & & 1.1.2 Tidak dilakukan uji tangki berkala \\
\hline & & $\underline{1.2 \text { Tangki korosi }}$ & & & $\underline{\text { 1.2.1 Lapisan cat mengelupas }}$ \\
\hline & & & & & 1.2.2 Gas sintesa amonia menitridasi logam \\
\hline & & 1.3 Material tangki mengalami & & & 1.3.1 Perawatan buruk \\
\hline & & penipisan dan fatigue & & & 1.3.2 Umur pemakaian \\
\hline & \multirow[t]{18}{*}{ 2. Sambungan pipa inlet bocor } & \multirow[t]{7}{*}{$\underline{2.1 \text { Fail close }} \underline{\mathrm{FCV}-860(\mathrm{Q})}$} & \multirow{3}{*}{$\begin{array}{l}\text { 2.1.1 Perbedaan tekanan di dalam } \\
\text { tangki dan tekanan input }\end{array}$} & \multirow[t]{3}{*}{ 2.1.1.1 Pressure indicator rusak } & 2.1.1.1.1 Perawatan buruk \\
\hline & & & & & 2.1.1.1.2 Umur pemakaian \\
\hline & & & & & $\begin{array}{l}\text { 2.1.1.2 Pemeriksaan operator control room } \\
\text { amonia }\end{array}$ \\
\hline & & & \multirow{3}{*}{\multicolumn{2}{|c|}{ 2.1.2 Kesalahan setting tekanan FCV }} & 2.1.2.1 Human error \\
\hline & & & & & 2.1.2.2 Pressure indicator error /jarang \\
\hline & & & & & dikalibrasi \\
\hline & & & \multirow{2}{*}{\multicolumn{2}{|c|}{ 2.1.3 Flow indicator (FI-860) rusak }} & 2.1.3.1 Perawatan buruk \\
\hline & & & & & 2.1.3.2 Umur pemakaian \\
\hline & & \multirow{7}{*}{$\underline{2.2 \text { Line pipa } \mathrm{NH} 3 \text { over pressure }}$} & \multirow[t]{3}{*}{$\underline{2.2 .1 \text { Build up pressure pada pipa }}$} & \multirow[t]{3}{*}{ 2.2.1.1 Kerusakan komponen pipa } & 2.2.1.1.1 Perawatan buruk \\
\hline & & & & & 2.2.1.1.2 Umur pemakaian \\
\hline & & & & & 2.2.1.2 Kesalahan setting pompa \\
\hline & & & \multirow{4}{*}{$\begin{array}{l}\text { 2.2.2 Block valve (BV-A) gagal } \\
\underline{\text { menutup }}\end{array}$} & \multirow[t]{2}{*}{ 2.2.2.1 Block valve leak } & 2.2.2.1.1 Umur pemakaian \\
\hline & & & & & 2.2.2.1.2 Perawatan buruk \\
\hline & & & & \multirow[t]{5}{*}{ 2.2.2.2 Kerusakan komponen } & 2.2.2.2.1 Umur pemakaian \\
\hline & & & & & 2.2.2.2.2 Perawatan buruk \\
\hline & & 2.3 Daya tahan sambungan terbatas & \multirow[t]{3}{*}{ 2.3.1 Pengelas tidak kompeten } & & 2.3.1.1 Kurangnya pengawasan saat pengerjaan \\
\hline & & & & & $\underline{\text { 2.3.1.2 Kurangnya pelatihan }}$ \\
\hline & & & & & 2.3.2 Umur pemakaian \\
\hline
\end{tabular}




\section{Lanjutan Tabel 3}

\begin{tabular}{|c|c|c|c|c|c|}
\hline Top Event & Intermediate event 1 & Intermediate event 2 & Intermediate event 3 & Intermediate event 4 & Basic cause \\
\hline \multirow{23}{*}{$\begin{array}{l}\text { Tangki } \\
\text { penyimpanan } \\
\text { mengalami } \\
\text { kebocoran }\end{array}$} & \multirow[t]{13}{*}{ 3. Over pressure tank } & \multirow{4}{*}{$\begin{array}{l}\text { 3.1 Pressure safety valve (PSV-872) } \\
\text { tidak berfungsi }\end{array}$} & 3.1.1 Kerusakan komponen & & 3.1.1.1 Umur pemakaian \\
\hline & & & spring/per & & 3.1.1.2 Tekanan melebihi desain $(>100 \mathrm{~g} / \mathrm{cm} 2)$ \\
\hline & & & & & 3.1.1.3 Perawatan buruk \\
\hline & & & & & $\underline{3.1 .2 ~ J a r a n g ~ d i k a l i b r a s i ~}$ \\
\hline & & \multirow[t]{9}{*}{$\underline{3.2 \text { Build up pressure tank }}$} & \multirow{6}{*}{$\begin{array}{l}\underline{\text { 3.2.1 Refrigerant }} \text { tidak berfungsi } \\
\underline{\text { ecara maksimal }}\end{array}$} & \multirow[t]{2}{*}{ 3.2.1.1 Masalah mekanis } & 3.2.1.1.1 Kerusakan komponen compressor \\
\hline & & & & & 3.2.1.1.2 Umur pemakaian \\
\hline & & & & \multirow[t]{7}{*}{ 3.2.1.2 Failed to pump } & 3.2.1.2.1 Gasket cylinder head bocor \\
\hline & & & & & 3.2.1.2.2 Katup discharge dan suction bocor \\
\hline & & & & & 3.2.1.2.3 Listrik drop/mati \\
\hline & & & & & lama \\
\hline & & & \multirow{3}{*}{$\begin{array}{l}\underline{3.2 .2 \text { Indikator tekanan tidak }} \\
\underline{\text { berfungsi }}\end{array}$} & & 3.2.2.1 Pressure gate rusak \\
\hline & & & & & 3.2.2.2 Pressure gate jarang dikalibrasi \\
\hline & & & & & \\
\hline & \multirow{10}{*}{ 4. Low pressure tank } & \multirow{5}{*}{$\begin{array}{l}\text { 4.1 Evaporator tidak bekerja secara } \\
\underline{\text { maksimal }}\end{array}$} & \multirow[t]{2}{*}{ 4.1.1 Tekanan NH3 kecil } & & 4.1.1.1 Tekanan NH3 yang masuk rendah \\
\hline & & & & & 4.1.1.2 Strainer kotor/tersumbat \\
\hline & & & \multirow[t]{3}{*}{ 4.1.2 NH3 lama panas } & \multirow[t]{3}{*}{ 4.1.2.1 Electric heater rusak } & 4.1.2.1.1 Perawatan buruk \\
\hline & & & & & 4.1.2.1.2 Umur pemakaian \\
\hline & & & & & 4.1.2.2 Gangguan listrik \\
\hline & & \multirow{3}{*}{\multicolumn{2}{|c|}{$\begin{array}{l}\text { 4.2 Vacuum breacker } \\
\text { bekerja maksimal }\end{array}$}} & & 4.2.1.1 Kerusakan komponen \\
\hline & & & & & 4.2.1.2 Umur pemakaian \\
\hline & & & & & 4.2.2 Tekanan NH3 kecil \\
\hline & & \multirow{2}{*}{\multicolumn{2}{|c|}{$\underline{4.3 \text { Indikator tekanan tidak berfungsi }}$}} & & 4.3.1 Pressure gauge rusak \\
\hline & & & & & 4.3.2 Pressure gauge jarang dikalibrasi \\
\hline
\end{tabular}




\section{KESIMPULAN}

Risiko yang paling tinggi pada kebocoran tangki penyimpanan amonia adalah pada fail close FCV dengan nilai sebesar 16. Risiko kebocoran tangki memberikan dampak dengan skala besar karena dapat mencemari lingkungan kerja pabrik dan lingkungan sekitar (permukiman). Basic cause kebocoran amonia ke lingkungan yang sering muncul adalah umur pemakaian, perawatan buruk, kesalahan setting, kerusakan komponen.

\section{DAFTAR PUSTAKA}

Asfahl, C.R., (1999), Industrial safety and health management, Prentice Hall Inc, New Jersey, USA

Bai Z, Dong Y, Wang Z, Zhu T. (2006) Emission of ammonia from indoor concrete wall and assessment of human exposure. Environ. Int.;32:303-311

Burlikowska M.D., (2011), Application of FMEA method in enterprise focused on quality, Journal of Achievements in Materials and Manufacturing Engineering, vol 45 issue 1, Pp.89-102

Bhattercharjee G, Bhattacharya S., Gangopadhyay R.K. and Das S.K.., (2012), Accidental Emission of Ammonia from Cold Storage and Ice Factory in Kolkata and its Remedial Action, Bonfring International Journal of Industrial Engineering and Management Science, Vol. 2, No. 3, September 2012

Yilang H, Xiaoli Y, Chao H., (2014), Analysis of Liquid Ammonia Leakage Accidents based on Safety System Engineering Theory, International Journal of Business and Social Science Vol. 5 No. 1, 220-226

ILO (1991). Prevention Of Major Industrial
Kavianian, H.R. dan Wentz, C.A., (1990), Occupational and environmental safety engineering and management, Van Nostrand Reinhold, New York, USA

Sultan L, Haq J, (2011), Risk Analysis Method: FMEA/FMECA in the Organizations, International Journal of Basic \& Applied Sciences IJBAS-IJENS Vol: 11 No: 05, 49-57

Lewis, R.J.,(1996) SAX's Dangerous Properties of Industrial Materials. 9th ed., Wiley-Interscience, New York

Petrokimia, (2010), Prosedur penerapan manajemen risiko

Plog, B.A and Quinlan, P.J., (2002), Fundamental of industrial hygiene, National safety council, USA

Rakesh, R., Jos B.C., Mathew, D., (2013), FMEA Analysis for Reducing Breakdowns of a Sub System in the Life Care Product Manufacturing Industry, International Journal of Engineering Science and Innovative Technology (IJESIT), volume 2, Issue 2, Pp.218-225

White E.S., (1971), A case of near fatal ammonia gas poisoning. J. Occupational. Medicine, Vol.13, Pp. 543-550

Jie, JI., Xiaoxia, C., Xuefeng H., (2014), Rapid simulation and visualization analysis of liquid ammonia tank leakage risk, Procedia Engineering Vol. 84, 682-688

Roy P.K., Bhatt A., Kumar B., Kaur S., Rajagopal C., (2011), Consequence and risk assessment: Case study of an ammonia storage facility, ARCH. ENVIRON. SCI., Vol. 5, 25-36. 